\title{
The importance of inhaler devices: the choice of inhaler device may lead to suboptimal adherence in COPD patients
}

This article was published in the following Dove Press journal:

International Journal of COPD

29 October 2015

Number of times this article has been viewed

Josep Darbà'

Gabriela Ramírez ${ }^{2}$

Antoni Sicras ${ }^{3}$

Pablo Francoli ${ }^{4}$

Saku Torvinen ${ }^{5}$

Rainel Sánchez-de la Rosa ${ }^{4}$

'Department of Economics, Universitat de Barcelona, ${ }^{2} \mathrm{BCN}$ Health Economics and Outcomes Research SL, ${ }^{3}$ Dirección de Planificación, Badalona Serveis Assistencials, SA, Barcelona, ${ }^{4}$ Medical Department, TEVA Pharmaceutical, Madrid, Spain; ${ }^{5}$ Market Access Department, TEVA Pharmaceutical Europe BV, Amsterdam, the Netherlands
Correspondence: Josep Darbà Department of Economics, Universitat de Barcelona, Diagonal 690, 08034 Barcelona, Spain

Email darba@ub.edu
Objective: This study aims to identify factors associated with poor adherence to COPD treatment in patients receiving a fixed-dose combination (FDC) of inhaled corticosteroids and long-acting $\beta_{2}$-agonist (ICS/LABA), focusing on the importance of inhaler devices.

Methods: We conducted a retrospective and multicenter study based on a review of medical registries between 2007 and 2012 of COPD patients $(n=1,263)$ treated with ICS/LABA FDC, whose medical devices were either dry powder inhalers (DPIs) or pressurized metered-dose inhalers (pMDI). Medication adherence included persistence outcomes through 18 months and medication possession ratios. Data on exacerbations, comorbidities, demographic characteristics, and health care resource utilization were also included as confounders of adherence.

Results: The analyses revealed that COPD patients whose medication was delivered through a DPI were less likely to have medication adherence compared to patients with pMDI, after adjusting for confounding factors, especially active ingredients. Younger groups of patients were less likely to be adherent compared to the oldest group. Smoker men were less likely to be adherent compared to women and non-smokers. Comorbidities decreased the probability of treatment adherence. Those patients that visited their doctor once a month were more likely to adhere to their medication regimen; however, suboptimal adherence was more likely to occur among those patients who visited more than three times per month their doctor. We also found that worsening of COPD is negatively associated with adherence.

Conclusion: According to this study, inhaler devices influence patients' adherence to longterm COPD medication. We also found that DPIs delivering ICS/LABA FDC had a negative impact on adherence. Patients' clinic and socioeconomic characteristics were associated with adherence.

Keywords: adherence, inhaler technique, medication possession ratio (MPR), dry powder inhalers (DPIs), pressurized metered-dose inhalers (pMDIs), persistence

\section{Introduction}

COPD causes specific inflammatory cell types and structural changes in the airways that determine the severity of this condition. In Spain, chronic lung diseases were the fourth leading cause of mortality in $2008 .{ }^{1}$ Furthermore, recent studies have reported that $\sim 10.2 \%$ of Spanish population between 40 and 80 years have COPD, ${ }^{2}$ but its under-diagnosis is frequent, and it is estimated that $73 \%$ of COPD cases have not been diagnosed. ${ }^{3}$ These characteristics make COPD already a very costly condition, which is estimated to be equivalent to $0.2 \%$ of Spanish gross domestic product. ${ }^{2}$

Pharmacological treatment should adjust to each patient, guided by severity of symptoms, risk of exacerbations, and patient's response. Maintenance treatment 
of COPD relies on inhaled agents to control symptoms and/or complications of the disease and to prevent exacerbations. ${ }^{1}$ Although these effects are required, inhaled pharmacological treatment depends on the efficacy of inhaler devices, patient's ability, and precision for using it; ${ }^{4,5}$ the reliability of devices for delivering the medicine directly to patients' lungs; 6,7 and patient's compromise to comply timing, dosage, and frequency of medication taking. ${ }^{8,9}$ Suboptimal adherence within chronic conditions has been largely documented. ${ }^{10,11}$ Specifically, the lack of adherence toward medication regime can cause progression of COPD, more severity of symptoms and exacerbations, hospitalization, and detriment of the quality of life among COPD patients. ${ }^{12-14}$ Medication adherence is a complex issue that can be defined as the degree to which a patient's medication-taking behavior and/or executing lifestyle changes correspond with agreed recommendations from a health care professional with respect to timing, dosage, and frequency. ${ }^{8,11}$ Over the last few years, researchers from several disciplines raised that adherence is an important problem given that is influenced not only by the increasingly complexity of lifelong therapy regimens but also by multiple clinical and nonclinical factors, to which we have to add the sociodemographic changes of a population aging. ${ }^{15}$ These aspects represent a challenge for national health care systems worldwide that should be analyzed from a multidisciplinary perspective. .,6,13,14 $^{-1}$

Although inhaled corticosteroids and long-acting $\beta_{2}$-agonist (ICS/LABA) fixed-dose combinations (FDCs) have shown to relieve COPD symptoms similarly, recent research has shown that inhaler technique might affect adherence and hence efficacy of pharmacological treatment. ${ }^{2-4}$ Inhaler technique is different between dry powder inhalers (DPIs) and pressurized metered-dose inhalers (pMDIs). Each of the devices is associated with procedure, which is also affected by the ability of patients to handle it. The aim of this study was to examine medication adherence in COPD patients, focusing on the associations between adherence with COPD medication and inhaler devices, such as DPI and pMDI, while adjusting for the potential effect of the active ingredients. Moreover, some other factors that could be affecting medication adherence, such as clinical or socioeconomic characteristics of patients, were also analyzed.

\section{Materials and methods}

\section{Study sample}

We conducted a retrospective and multicenter study based on a review of medical registries of COPD patients treated with
ICS/LABA FDC, whose inhaler devices were either DPIs or pMDIs. Diagnosis was spirometry based, which was useful to classify patients into three categories: mild, moderate, and severe. Criteria were always the doctor's opinion. The study population included patients attending primary care centers, whose population was mostly urban, with a low-to-medium socioeconomic level.

The study sample comprised all COPD patients, who initiated their treatment with ICS/LABA FDC between January 1, 2007 and June 30, 2014. Moreover, patients fulfilled the following characteristics: 1) aged $\geq 35,2$ ) time of diagnosis $>3$ years, and 3) were required to have registries with regular monitoring for 18 months (ie, those who were part of the long-term prescription program to obtain prescriptions with a confirmed record of the daily dosage, time interval, and duration of each treatment) $(n=1,645)$. We excluded patients who were transferred outside the area, patients permanently institutionalized, patients who died during the period of analysis $(n=382)$, and patients who presented clinical history of pulmonary emphysema, bronchiectasis, cystic fibrosis, and bronchial neoplasia.

\section{Data source and variables}

This retrospective study used integrated medical and pharmacy claims' data to identify the impact of inhaler technique toward adherence outcomes. Database contains information on COPD treatments with ICS/LABA FDC according to the Anatomical Therapeutic Chemical Classification System. We linked each treatment to its inhaler device, which could be a DPI or a pMDI. Thus, within DPIs were included Turbuhaler ${ }^{\circledR}$, Accuhaler ${ }^{\circledR}$, and NEXThaler ${ }^{\circledR}$ that delivered formoterol/budesonide, salmeterol/fluticasone, and formoterol/beclomethasone, respectively. pMDIs delivered either formoterol/beclomethasone or salmeterol/fluticasone. Database is managed by Badalona Serveis Assitencials, which provides services to ten primary care centers, one hospital, and one sociohealth center. Ethics approval for the database to be used for research was granted by the Ethics Committee of the Hospital Universitari Germans Trías i Pujol.

Information on persistence was obtained for 1 year and half, indicating whether patient kept taking that treatment (persistence) at the third, sixth, 12th, and 18th months (Figures 1 and 2). Information on medication possession was also obtained by patient's refill count as well as data on duration by the number of days patient should be consuming the medication. Demographic characteristics of 
Treatment persistence - third month

(by inhaler device)

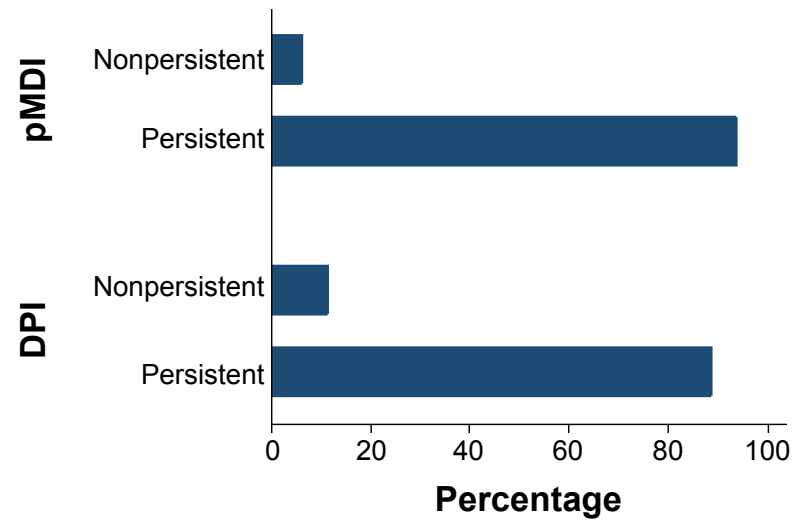

Treatment persistence - 12th month (by inhaler device)

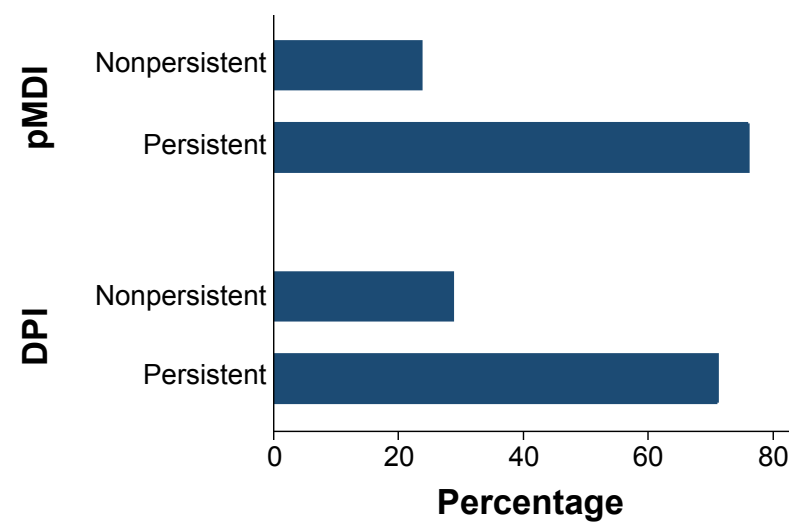

Figure I Percentage of persistent patients at the third, sixth, 12th, and 18th months. Abbreviations: pMDI, pressurized metered-dose inhaler; DPI, dry powder inhaler.

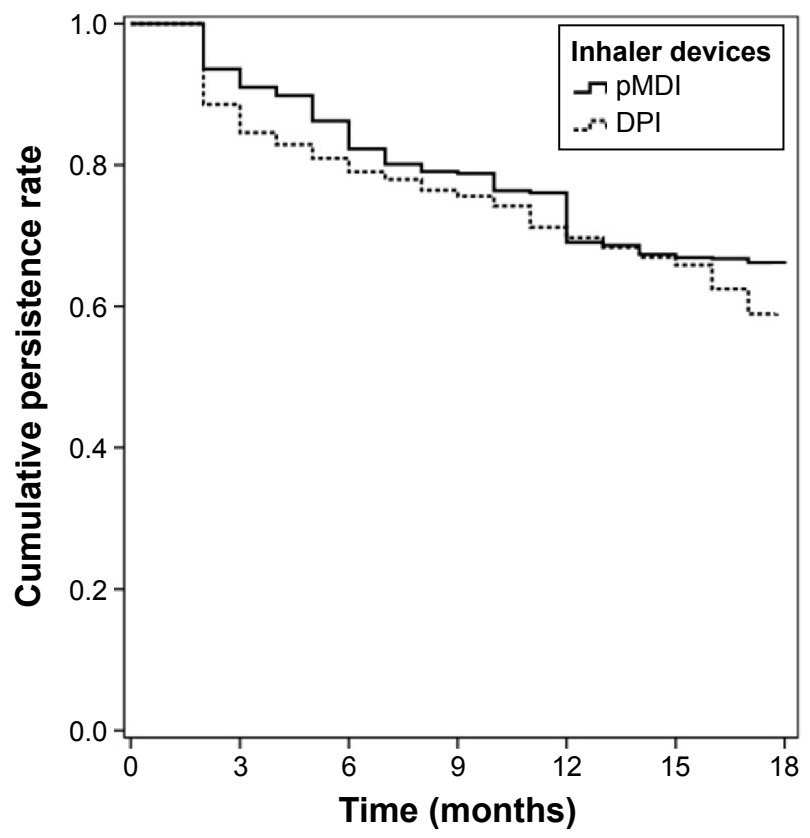

Figure 2 Medication persistence.

Abbreviations: pMDI, pressurized metered-dose inhaler; DPI, dry powder inhaler.
Treatment persistence - sixth month (by inhaler device)

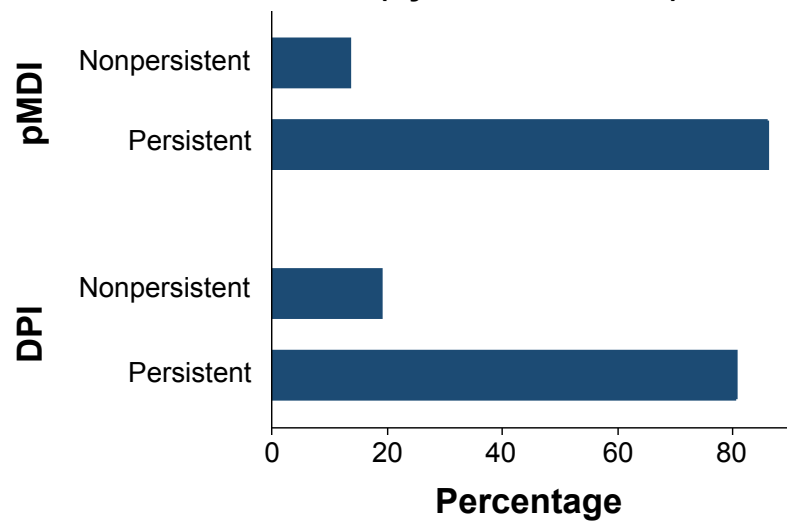

Treatment persistence - 18th month (by inhaler device)

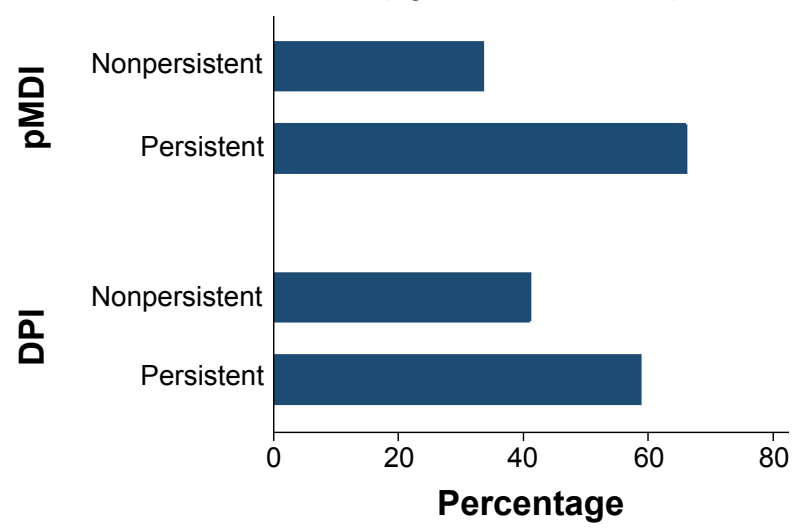

this sample were age, sex, and whether the patient was retired or not.

Furthermore, we gathered data of other potential confounders of medication adherence. A number of mild/ moderate exacerbations and acute events, defined by the GesEPOC recommendations, ${ }^{2}$ were collected. Medications, such as oral corticosteroids, systemic antibiotics, short-acting $\beta_{2}$-agonist, short-acting anticholinergic, and systemic $\beta_{2}$-agonists, to treat the symptoms and complications of COPD were available. Clinical data on comorbidities were included. Basically, it was indicated whether the patients suffered from simultaneous conditions, such as hypertension, diabetes, dyslipidemia, arthritis, osteoarthritis, depression, and dementia. Also severe events, including failures, ischemic heart disease, cerebrovascular diseases, and neoplasm, were indicated. Behavior attitudes that could derive to higher risk of developing a disease, for instance, obesity, smoking habit, and alcoholism, were also included as comorbidities. We had also access to number of visits to 
the physician during the period of study. Pharmacy administrative database also stores gross amount of pharmaceutical expenditure per patient. Data were adapted into our model by obtaining patient's average cost per month because Spanish patients have low co-payment levels for their medication; we approximated the potential cost that patients could face each month.

\section{Calculation of patient's medication adherence}

To calculate adherence, we utilized the medication possession ratio (MPR), which is calculated by dividing the number of days supplied for a given medication by the number of days in the study, and persistence data. ${ }^{16}$ Persistence is defined as the duration of time from initiation to discontinuation of therapy. Clinical outcomes are affected not only by how well patients take their medication but also by how long they take them, so the effect on how well patients take ICS/LABA FDC can be observed without being disturbed by discontinuation. First, we identified patients who last 18 months with their medication, which implied that they were persistent. These patients were analyzed to obtain adherence by using the MPR. Therefore, within these persistent patients, we applied a cut-point of $90 \%$ to the MPR. Since MPR tends to be overestimated, 9,17 we also increased the limit to consider medication adherence. We had an ordered categorical variable, which showed to be very useful to identify persistence and adherence patterns: patients first need to be persistent with their treatment, and then they need to comply with their prescriptions. ${ }^{4,9}$ This variable reflects patients who are not neither persistent nor adherent, patients who are persistent but nonadherent, and patients who are persistent and showed adherence to their medication (Figure 3). Finally, to check the robustness of our findings, we decided to use the most common cut-point that is $80 \%$ to the MPR. ${ }^{13,18}$ This analysis focuses on factors that diminish medication adherence.

\section{Analysis}

To illustrate the distribution of patient's adherence within each medical device (DPI or pMDI), we tabulated sample characteristics for patients using either a DPI or a pMDI (Table 1). Univariate associations between medication adherence, medical device, and several confounders, such as age, comorbidities, exacerbations, severity of COPD, medication to treat COPD, and drug cost, were analyzed (Table 2). To perform basic analysis, we only included statistically significant variables from the univariate analysis into the first specification (Table 3).

With reference to health care utilization, visits to physicians were categorized in order to explore the association of having, on average, none or one visit per month, between one and three visits per month, and more than three visits per month (baseline will be none or one visit per month). We considered a variable for comorbidity status, which was categorized as having one, two, or more than three conditions, besides COPD.

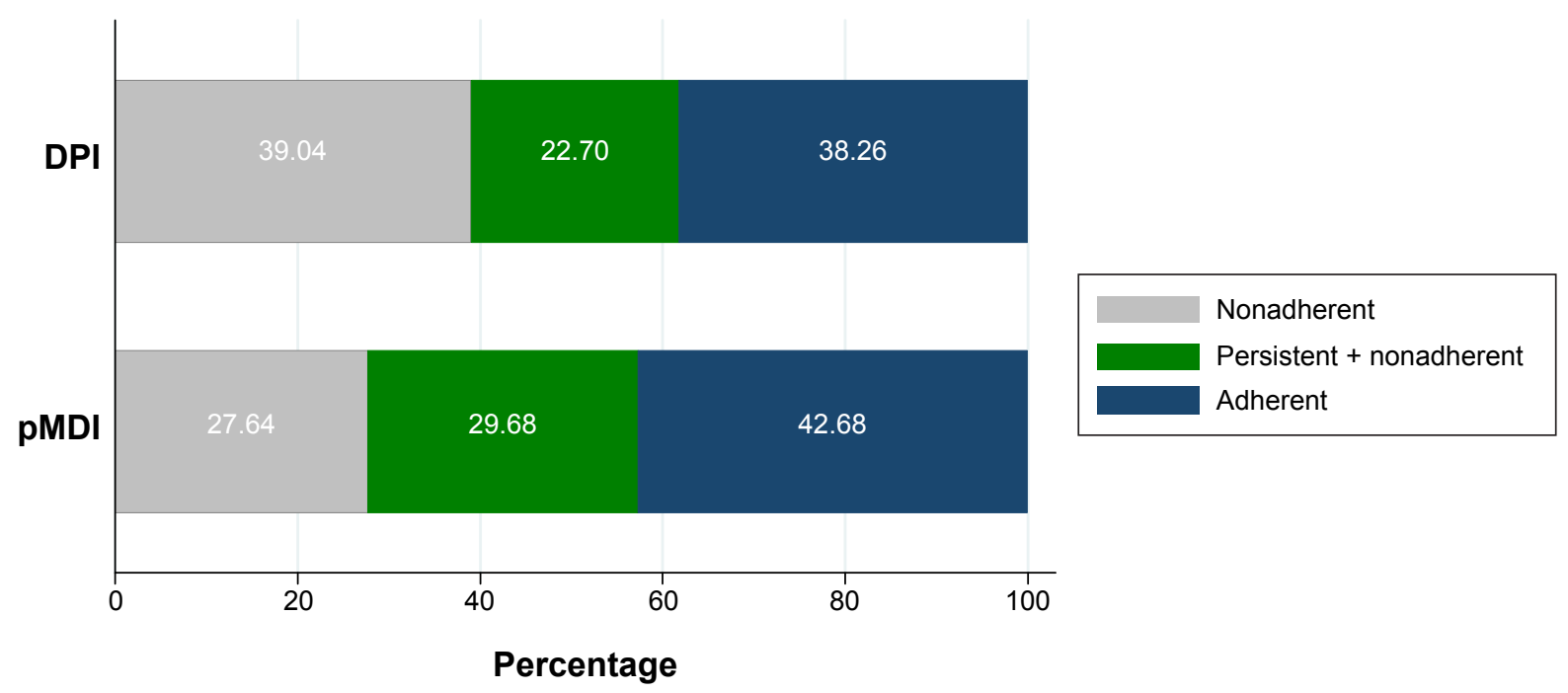

Figure 3 Percentage of adherent patients by each inhaler device $(n=I, 263)$.

Notes: Nonpersistent patient $=$ patient who discontinued their therapy before the 18 th month, persistent + nonadherent patient $=$ patient who did not discontinue therapy but was $<90 \%$ of the MPR, and adherent patient = patient who did not discontinue their therapy but was $>90 \%$ of the MPR.

Abbreviations: pMDI, pressurized metered-dose inhaler; DPI, dry powder inhaler; MPR, medication possession ratio. 
Table I Characteristics of COPD patients according to the type of inhaler device: DPI or pMDI

\begin{tabular}{|c|c|c|c|c|}
\hline Characteristics & pMDI $(n=492)$ & DPI $(n=77 I)$ & Total $(n=1,263)$ & $P$-value \\
\hline Male (\%) & 38.95 & 61.04 & 83.45 & 0.735 \\
\hline Age, mean (SD) (years) & $70.54(10.37)$ & $70.66(9.91)$ & 70.61 & 0.326 \\
\hline $39-50$ & 5.28 & 3.50 & 4.20 & - \\
\hline $5 I-6 \mid$ & 12.40 & 13.75 & 13.22 & - \\
\hline $62-71$ & 33.54 & 32.68 & 33.02 & - \\
\hline $72-83$ & 40.04 & 40.73 & 40.46 & - \\
\hline $84-97$ & 8.74 & 9.34 & 9.11 & - \\
\hline Retired status (\%) & 87.2 & 89.23 & 88.44 & 0.966 \\
\hline Time since COPD was diagnosed, mean (SD) (years) & $15.0(5.19)$ & $15.44(5.04)$ & $15.38(5.10)$ & 0.994 \\
\hline \multicolumn{5}{|l|}{ Severity of COPD (\%) } \\
\hline Mild & 17.89 & 14.79 & 15.99 & - \\
\hline Moderate & 77.85 & 80.80 & 79.65 & - \\
\hline Severe & 4.27 & 4.41 & 4.35 & - \\
\hline $\mathrm{FEV}_{\text {, }}$, mean (SD) & $76.6(9.9)$ & $79.1(9.9)$ & $79.2(9.9)$ & 0.256 \\
\hline \multicolumn{5}{|l|}{ ICS/LABA FDC (\%) } \\
\hline Formoterol/beclomethasone & 24.59 & 17.12 & 20.03 & - \\
\hline Formoterol/budesonide & 0.0 & 51.88 & 31.67 & - \\
\hline Salmeterol/fluticasone & 75.41 & 31.00 & 48.30 & - \\
\hline $\begin{array}{l}\text { Exacerbations (\%) (binary on whether patients suffered an } \\
\text { exacerbation or not) }\end{array}$ & 36.99 & 42.15 & 40.14 & 0.068 \\
\hline Moderate & 31.5 & 36.96 & 34.84 & $<0.001$ \\
\hline Acute & 16.06 & 14.92 & 15.36 & 0.630 \\
\hline \multicolumn{5}{|l|}{ Comorbidities (\%) } \\
\hline Obesity & 38.62 & 40.86 & 39.98 & 0.650 \\
\hline Smoking & 21.14 & 19.58 & 20.19 & 0.743 \\
\hline Alcoholism & 6.91 & 6.10 & 6.41 & 0.891 \\
\hline Cerebrovascular disease & 34.15 & 35.80 & 35.15 & 0.948 \\
\hline Hypertension & 59.35 & 60.57 & 60.10 & 0.650 \\
\hline Diabetes & 28.66 & 28.40 & 28.50 & 0.732 \\
\hline Dyslipidemia & 52.44 & 49.68 & 50.75 & 0.518 \\
\hline Osteoarthritis & 8.40 & 6.28 & 7.17 & 0.099 \\
\hline Arthritis & 20.42 & 21.16 & 20.73 & 0.714 \\
\hline Stroke & 23.78 & 25.42 & 24.78 & 0.510 \\
\hline Ischemic heart disease & 16.06 & 15.30 & 15.60 & 0.948 \\
\hline Failures & 25.20 & 27.11 & 26.37 & 0.987 \\
\hline Dementia & 6.50 & 6.87 & 6.73 & 0.964 \\
\hline Depression & 24.19 & 26.72 & 25.73 & 0.855 \\
\hline Neoplasm & 16.26 & 17.12 & 16.79 & 0.846 \\
\hline Other medication to treat COPD (\%) & 84.76 & 84.95 & 84.88 & - \\
\hline Oral corticosteroids & 8.54 & 8.17 & 8.31 & 0.856 \\
\hline Systemic antibiotics & 2.7 & 7.0 & 5.9 & $<0.05$ \\
\hline SABA & 80.3 & 80.4 & 80.3 & 0.862 \\
\hline Short-acting anticholinergic & 57.72 & 55.12 & 56.14 & 0.364 \\
\hline Number of visits to doctor, mean (SD) & $18.99(\mid 3.28)$ & $21.99(14.24)$ & $20.82(13.94)$ & $<0.001$ \\
\hline Average cost per month, mean (SD) (Euros) & $64.95(43.54)$ & $62.75(44.10)$ & $63.60(43.88)$ & 0.3852 \\
\hline Mean of total health care cost per patient, mean (SD) (Euros) & $1,920.99(1,427.22)$ & $2,013(1,716.5)$ & $1,977(1,716.5)$ & 0.3527 \\
\hline
\end{tabular}

Note: Patients' characteristics who visited their primary care center between January 2007 and June 2014.

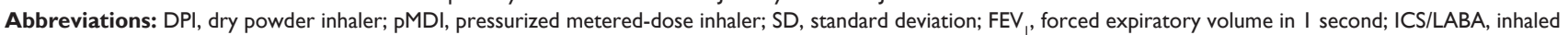
corticosteroids and long-acting $\beta_{2}$-agonist; FDC, fixed-dose combination; COPD, chronic obstructive pulmonary disease; SABA, short-acting $\beta_{2}$-agonist.

Moreover, to consider the potential heterogeneity sources across age groups, the continuous variable age was split into five groups. Utilization of medication to treat COPD, besides ICS/LABA FDCs, was combined in a single variable that captures number of medication took per patient during the period of study. We did not analyze each pattern by itself because we are interested on adherence patterns in patients attempting to take ICS/LABA FDC chronically. Tables 2-4 contain results expressed in percentage points (pp) and odd ratios. 
Table 2 Univariate analysis of each potential confounders of adherence

\begin{tabular}{|c|c|c|c|c|c|}
\hline \multirow[t]{2}{*}{ Explanatory variables } & \multirow[t]{2}{*}{ Category } & \multicolumn{4}{|l|}{ Adherence $(n=I, 263)$} \\
\hline & & Percentage points & Odds ratios & $95 \% \mathrm{Cl}$ & $\overline{P \text {-value }}$ \\
\hline Medical device DPI (baseline pMDI) & & -7.85 & 0.72 & $0.583-0.8686$ & 0.002 \\
\hline \multirow[t]{2}{*}{ ICS/LABA FDC (baseline formoterol/beclometasone) } & Formoterol/budesonide & -3.58 & 0.858 & $0.640-1.150$ & 0.308 \\
\hline & Salmeterol/fluticasone & 2.98 & 1.13 & $0.860-1.487$ & 0.378 \\
\hline \multirow[t]{2}{*}{ Therapy line (baseline first line) } & Second line & 16.55 & 1.96 & $1.363-2.814$ & 0.000 \\
\hline & Third line & 24.75 & 2.75 & $1.222-6.186$ & 0.011 \\
\hline Age & & -0.35 & 0.98 & $0.975-0.995$ & 0.004 \\
\hline Sex (baseline men) & & 6.29 & 1.30 & $0.985-1.715$ & 0.063 \\
\hline Retired status & & -3.14 & 0.87 & $0.638-1.204$ & 0.417 \\
\hline Obesity & & 4.61 & 1.21 & $0.985-1.493$ & 0.069 \\
\hline Smoking & & 7.63 & 1.37 & $1.066-1.777$ & 0.014 \\
\hline Stroke & & -6.73 & 0.75 & $0.594-0.957$ & 0.020 \\
\hline Cerebrovascular disease & & -6.72 & 0.75 & $0.608-0.935$ & 0.010 \\
\hline Hypertension & & 0.89 & 1.04 & $0.843-1.278$ & 0.724 \\
\hline Diabetes & & -1.80 & 0.93 & $0.738-1.164$ & 0.517 \\
\hline Dislipemia & & -1.89 & 0.92 & $0.753-1.133$ & 0.448 \\
\hline Osteoarthritis & & 0.87 & 1.03 & $0.808-1.330$ & 0.775 \\
\hline Arthritis & & -0.31 & 0.98 & $0.654-1.489$ & 0.951 \\
\hline Alcoholism & & 6.51 & 1.31 & $0.863-1.993$ & 0.203 \\
\hline Ischemic cardiomyopathy & & -0.83 & 0.96 & $0.730-1.277$ & 0.807 \\
\hline Failures & & 2.89 & 1.12 & $0.895-|.42|$ & 0.306 \\
\hline Dementia & & -9.18 & 0.68 & $0.446-1.309$ & 0.075 \\
\hline Depression & & -2.07 & 0.92 & $0.727-1.156$ & 0.465 \\
\hline Neoplasm & & 3.93 & 1.17 & $0.896-1.548$ & 0.239 \\
\hline Number of exacerbations & & 4.48 & 1.21 & $1.114-1.311$ & 0.000 \\
\hline Number of severe exacerbations & & -9.41 & 0.91 & $0.684-1.210$ & 0.518 \\
\hline Number of mild/moderate exacerbations & & 5.77 & 1.28 & I.165-I.403 & 0.000 \\
\hline \multirow[t]{2}{*}{ Severity of COPD (baseline mild) } & Moderate & 4.80 & 1.23 & $0.930-1.619$ & 0.148 \\
\hline & Severe & 22.15 & 2.47 & $1.374-4.459$ & 0.003 \\
\hline Time since COPD was diagnosed & & -1.72 & 0.93 & $0.909-0.947$ & 0.000 \\
\hline \multirow[t]{6}{*}{ Other medication to treat COPD } & & 5.66 & 1.27 & $1.181-1.375$ & 0.000 \\
\hline & Oral corticosteroids & 11.32 & 1.61 & $1.307-1.990$ & 0.000 \\
\hline & Systemic antibiotics & 14.83 & 1.87 & $1.444-2.430$ & 0.000 \\
\hline & SABA & 16.95 & 2.06 & $1.629-2.604$ & 0.000 \\
\hline & $\begin{array}{l}\text { Short acting } \\
\text { anticholinergic }\end{array}$ & 7.83 & 1.388 & I.130-I.707 & 0.002 \\
\hline & $\beta_{2}$ Agonists (systemic) & 6.82 & 1.33 & $0.903-1.956$ & 0.149 \\
\hline Long acting anticholinergic agents & & 13.56 & 1.77 & $1.393-2.260$ & 0.000 \\
\hline Cost & & -0.25 & 0.98 & $0.986-0.991$ & 0.000 \\
\hline Visits to doctor & & 0.41 & 1.017 & $1.009-1.25$ & 0.000 \\
\hline
\end{tabular}

Abbreviations: $\mathrm{Cl}$, confidence interval; DPI, dry powder inhaler; pMDI, pressurized metered-dose inhaler; ICS/LABA, inhaled corticosteroids and long-acting $\beta_{2}$-agonist; FDC, fixed-dose combination; COPD, chronic obstructive pulmonary disease; SABA, short-acting $\beta_{2}$-agonist.

\section{Results}

\section{Clinical and demographic characteristics}

Persistence rates were diminishing throughout 18 months and were similar among inhaler devices at the 18th month (Figures 1 and 2). We could identify the final proportion of adherent patients on the basis of methodology described in the "Calculation of patient's medication adherence" section. Remarkably higher rates of discontinuation were observed in patients using a DPI. However, patients who have medication adherence were similar in both groups (Figure 3).
Sociodemographic and clinical characteristics of 1,263 COPD patients tabulated by an inhaler device are shown in Table 1 . A total of $38.95 \%$ of patients used a pMDI and $61.05 \%$ used a DPI during the time of study. The mean age of patients was 71 years, most of them were retired ( $88.44 \%$ ), and $83.45 \%$ of them were men. Time since diagnosis (in years) was similar in both groups. The most frequent comorbidity observed in this sample was hypertension (60.1\%), followed by dyslipidemia $(50.75 \%)$, which were very similar in both groups. Patients with moderate COPD represent $79.65 \%$, and the distribution 
Table 3 Multivariate results of potential confounders of adherence

\begin{tabular}{|c|c|c|c|c|c|c|}
\hline \multirow{3}{*}{$\begin{array}{l}\text { Explanatory variables } \\
\left(\text { McFadden's } R^{2}=0.07 \mathrm{II}\right)\end{array}$} & \multicolumn{6}{|l|}{ Adherence $(n=I, 263)$} \\
\hline & \multicolumn{3}{|c|}{ Without active ingredients } & \multicolumn{3}{|c|}{ Controlling for active ingredients } \\
\hline & Percentage points & Odd ratios & $95 \% \mathrm{Cl}$ & Percentage points & Odd ratios & $95 \% \mathrm{Cl}$ \\
\hline Medical device DPI (baseline pMDI) & $-9.95^{*}$ & $0.60^{*}$ & $0.48 \mathrm{I}-0.750$ & $-9.57^{*}$ & $0.6 I^{*}$ & $0.467-0.802$ \\
\hline \multicolumn{7}{|c|}{ ICS/LABA FDC (baseline formoterol/beclometasone) } \\
\hline Formoterol/budesonide & - & - & - & 2.07 & 1.11 & $0.798-1.556$ \\
\hline Salmeterol/fluticasone & - & - & - & 3.37 & 1.19 & $0.893-1.586$ \\
\hline \multicolumn{7}{|l|}{ Severity of COPD (baseline mild) } \\
\hline Persistent moderate & $11.22^{*}$ & $1.91 * *$ & $1.323-2.766$ & $11.65 *$ & $1.89 *$ & $|.3||-2.74|$ \\
\hline Persistent severe & 7.08 & 1.49 & $0.645-3.484$ & 6.74 & 1.47 & $0.632-3.426$ \\
\hline Time since COPD was diagnosed & $-1.15^{*}$ & 0.942 & $0.917-0.968$ & $-1.14 *$ & $0.94 *$ & $0.918-0.968$ \\
\hline \multicolumn{7}{|l|}{ Therapy line } \\
\hline Second & $10.13^{* *}$ & $1.637^{* *}$ & $1.125-2.380$ & $\left.10.2\right|^{* *}$ & $1.64 * *$ & $1.130-2.390$ \\
\hline Third & $20.45^{* *}$ & $2.624 * *$ & $1.077-6.361$ & $20.14^{* *}$ & $2.58^{*}$ & $1.063-6.305$ \\
\hline Age & -0.11 & 0.994 & $0.979-1.009$ & -0.12 & 0.99 & $0.978-1.009$ \\
\hline Sex & 4.02 & 1.23 & $0.16 \mathrm{I}-0.921$ & 0.41 & 1.23 & $0.923-1.644$ \\
\hline Obesity & 2.12 & 1.11 & $0.894-1.391$ & 1.94 & 1.10 & $0.885-1.379$ \\
\hline Smoking & 4.63 & 1.268 & $0.958-1.677$ & 4.50 & 1.260 & $0.952-1.667$ \\
\hline Stroke & -3.34 & 0.842 & $0.588-1.206$ & -3.21 & 0.848 & $0.592-1.214$ \\
\hline Cerebrovascular disease & -3.84 & 0.821 & $0.55 \mathrm{I}-1.222$ & -3.85 & 0.821 & $0.55 \mathrm{I}-1.222$ \\
\hline Exacerbations & $-6.20 * *$ & $0.72^{* *}$ & $0.529-1.001$ & $-6.57^{* *}$ & $0.714 * *$ & $0.517-0.984$ \\
\hline Mild/moderate exacerbations & $10.22 * *$ & $1.69 * *$ & I. $188-2.400$ & $10.62^{* *}$ & $1.72 * *$ & $1.210-2.457$ \\
\hline Long-acting anticholinergic agent & 2.77 & 1.15 & $0.838-1.584$ & 2.73 & 1.150 & $0.836-1.582$ \\
\hline Pharmacological cost & $-0.2 I^{*}$ & $0.989 *$ & $0.986-0.992$ & $-0.21 * *$ & $0.989 * *$ & $0.986-0.992$ \\
\hline Visits to doctor & $0.24 * *$ & $1.012^{* *}$ & $1.004-1.021$ & $0.24 * *$ & $1.012 * *$ & $|.004-1.02|$ \\
\hline
\end{tabular}

Notes: $* P<0.001$ and $* * P<0.05$

Abbreviations: $\mathrm{Cl}$, confidence interval; DPI, dry powder inhaler; pMDI, pressurized metered-dose inhaler; ICS/LABA, inhaled corticosteroids and long-acting $\beta_{2}$-agonist; FDC, fixed-dose combination; COPD, chronic obstructive pulmonary disease.

of disease severity is very similar across clusters. It is worth mentioning that the use of ICS/LABA FCD in COPD subjects is limited to severe or moderate-to-severe obstruction and common exacerbations; however, we observed patients classified as mild who use these therapies. Furthermore, one DPI included does not have indication for COPD in Spain but our sample shows that currently is being used with such a propose, which might be explained by a certain freedom to prescribe off-label. Almost half of the patients $(40.79 \%)$ experienced at least one exacerbation.

Table 2 contains results of univariate regressions. DPI utilization was negatively correlated with adherence; on the contrary, the effect of active ingredients was not statistically significant. Clinical characteristics, such as COPD severity, time since diagnosis, number of mild and moderate exacerbations, and some comorbidities, such as smoking and cerebrovascular diseases, were negatively correlated with adherence, except for moderate exacerbations that were positively correlated with it. None of the diseases that are mobility limiting were significant. Long-acting anticholinergic agents were positively correlated with adherence as well as most of the medication to treat COPD, except for systemic administration of $\beta_{2}$-adrenoceptor agonists that were not statically significant. Pharmaceutical costs were negatively correlated with adherence, and visits to physician were positively correlated with it.

\section{Inhaler technique and other confounders affecting patient's adherence to the COPD treatment}

Results are shown in Table 3 with and without active ingredient variable. Remarkably, variable for inhaler devices increased its significance $(P<0.001)$, and the probability of adherence by a patient using a DPI would be diminished by almost $10 \mathrm{pp}$ compared to that of a patient using pressurized inhalers. These measures were adjusted for confounders, and some of them were significant. For instance, time since diagnosis is negatively associated with medication adherence. In case of moderate exacerbations, the link is positive. Regarding health care resources, the coefficient of pharmaceutical cost would have a small negative impact on medication adherence, while the effect of doctor's visit is positive.

In Table 4, we present the results of the regression that provided the adjusted measures of association between the 
Table 4 Final specification: results of multivariable analysis examining the associations between inhaler devices for ICS/LABA FDC and adherence

\begin{tabular}{|c|c|c|c|}
\hline \multirow[t]{2}{*}{ Explanatory variables (McFadden's $R^{2}=0.2898$ ) } & \multicolumn{3}{|c|}{ Adherence $(n=1,263)$} \\
\hline & Percentage points & Odds ratio & $95 \% \mathrm{Cl}$ \\
\hline Medical device DPI (baseline pMDI) & $-5.38 *$ & $0.7 I^{*}$ & $0.521-0.970$ \\
\hline \multicolumn{4}{|l|}{ ICS/LABA FDC (baseline formoterol/beclomethasone) } \\
\hline Formoterol/budesonide & -0.38 & 0.97 & $0.661-1.440$ \\
\hline Salmeterol/fluticasone & 3.07 & 0.72 & $0.24 I-2.174$ \\
\hline \multicolumn{4}{|l|}{ Severity of COPD (baseline moderate) } \\
\hline Mild & $-9.81^{*}$ & $0.53^{*}$ & $0.300-0.960$ \\
\hline Severe & -5.15 & 0.72 & $0.24 I-2.174$ \\
\hline Time since COPD was diagnosed & $-0.78^{*}$ & $0.95^{*}$ & $0.923-0.981$ \\
\hline \multicolumn{4}{|l|}{ Therapy line (baseline first line) } \\
\hline Second line & -1.27 & 0.92 & $0.603-1.413$ \\
\hline Third line & 1.69 & I.II & $0.437-2.823$ \\
\hline Sex (baseline men) & 3.01 & 1.21 & $0.816-1.782$ \\
\hline Age (as a continuous variable) & $-1.23 * *$ & $0.96 * *$ & $0.887-0.966$ \\
\hline \multicolumn{4}{|l|}{ Age groups (baseline 87-97) } \\
\hline $39-51$ & $-34.04 * *$ & $0.99 *$ & $0.169-0.578$ \\
\hline $5 I-6 \mid$ & $-29.69 * *$ & $0.13 *$ & $0.036-0.501$ \\
\hline $6|-7|$ & $-23.04 * *$ & $0.212^{*}$ & $0.081-0.552$ \\
\hline $72-83$ & $-16.62 * *$ & $0.32^{* *}$ & $0.173-0.599$ \\
\hline Retired status & 5.05 & 1.37 & $0.736-2.563$ \\
\hline \multicolumn{4}{|l|}{ Number of comorbidities } \\
\hline 2 & -0.74 & 0.95 & $0.662-1.374$ \\
\hline 3 & $-10.96 *$ & $0.49 *$ & $0.282-0.864$ \\
\hline Obesity & 6.26 & 1.47 & $0.975-2.231$ \\
\hline Smoking & $14.52^{*}$ & $2.248^{*}$ & I.105-5.587 \\
\hline Smoking men & $-28.73 * *$ & $0.167^{* *}$ & $0.034-0.800$ \\
\hline Hypertension & $6.29 *$ & $1.48^{*}$ & $1.085-2.018$ \\
\hline Diabetes & 5.00 & 1.36 & $0.98 I-1.902$ \\
\hline Acute exacerbation & $-8.36^{*}$ & $0.59 *$ & $0.378-0.933$ \\
\hline Moderate exacerbation & 2.20 & 1.14 & $0.914-1.438$ \\
\hline Long-acting anticholinergic agents & 5.23 & 1.37 & $0.928-2.050$ \\
\hline Other medication to treat COPD & 2.44 & 1.16 & $0.995-1.362$ \\
\hline Additional visit to the doctor & $2.15^{* *}$ & $1.14 * *$ & $1.122-1.165$ \\
\hline \multicolumn{4}{|l|}{ Visits to doctor } \\
\hline Two times per month (on average) & $-33.88 * *$ & $0.11 * *$ & $0.797-0.165$ \\
\hline Three times per month (on average) & $-67.25^{* *}$ & $0.0028 * *$ & $0.009-0.007$ \\
\hline Average pharmacological cost per month & 0.04 & 1.00 & $0.999-1.006$ \\
\hline
\end{tabular}

Notes: $* P<0.05$ and $* * P<0.001$.

Abbreviations: ICS/LABA, inhaled corticosteroids and long-acting $\beta_{2}$-agonist; FDC, fixed-dose combination; Cl, confidence interval; DPI, dry powder inhaler; pMDI, pressurized metered-dose inhaler; COPD, chronic obstructive pulmonary disease.

inhaler technique and medication adherence and showed to fit the data better than previous models. This analysis revealed that patients treated with ICS/LABA FDC delivered by a DPI were less likely to adhere to their COPD treatment compared to patients that used a pMDI. By contrast, the variable that captures the association between ICS/LABA and adherence was not significant. Regarding disease severity, worsening of COPD is not negatively associated with adherence. This effect is not consistent with the coefficient of time since the diagnosis, which implies that the probability of medication adherence would decrease by $0.7 \mathrm{pp}$, for an extra year with COPD.
The categorical variable for the number of comorbidities shows that having more than three multiple conditions would impact negatively on medication adherence, despite most of the comorbidities in the previous regressions were not statistically significant. Regarding comorbidities, we found that hypertension was positively correlated with adherence as well as smoking. Regarding patients' characteristics, age appeared to be determinant, affecting adherence to treatment negatively. However, this effect becomes smaller as we moved to older age groups.

An additional acute exacerbation for COPD patients was negatively associated with medication adherence, but 
number of medication to treat COPD, besides ICS/LABA FDC, showed to be not significant. An additional visit to the doctor was positively associated with medication adherence. Conversely, more than one physician visit per month is negatively associated with adherence. Some other potential confounders, such as sex, concomitant medication, and moderate exacerbations, were not statistically significant for explaining adherence with COPD medication. Additionally, results of the interaction term of sex and smoking suggest that the probability of medication adherence was reduced for smoking men compared to smoking women and nonsmokers. Regarding health care resources, cost was not significant. Robustness check confirmed our results, and the effect of inhaler technique increases its significance toward suboptimal adherence $(P<0.001)$.

\section{Discussion}

These analyses revealed that after adjustment for confounding variables, especially the active agents, patients treated with ICS/LABA FCD delivered using a DPI (Accuhaler ${ }^{\circledR}$, NEXThaler $^{\circledR}$, and Turbuhaler $^{\circledR}$ ) were less likely to show adherence compared to patients treated with ICS/LABA FCD delivered using a pMDI. Results are striking because, despite the inclusion of several confounders of adherence, there was still a statistically significant coefficient of the variable of inhaler devices' utilization, suggesting that factors related only to inhaler devices might weaken probability of medication adherence. We can find critical errors of DPIs in the literature. The most frequently reported flaw is failure to exhale before inhaling and in consequence, failure to use a forceful and deep inhalation. ${ }^{19}$ Moreover, DPIs included in our analysis present errors regarding the metering of the dose and positioning the inhaler. ${ }^{19}$ Suboptimal adherence limits the efficacy of inhalation therapy, since there are negative impacts in outcomes as survival and cost as well as clinical outcomes. ${ }^{20,21}$ Although there is not an agreement on the situation that predisposes to inhaler misuse, the identification of associations between inhaler technique and patients' adherence shed some light on reasons why suboptimal adherence has become a major problem. . $18,22,23^{2}$

Our results are consistent with the previous analyses that described several factors affecting medication adherence negatively. ${ }^{8,24,25}$ In our analysis, we identified factors that affect adherence of long-term inhalation therapy in COPD patients. Age was negatively associated with adherence. ${ }^{26}$ This effect is consistent with time since diagnosis, which indicates a negative in adherence as time passes toward adherence to long-term therapy. However, the effect decreases along with age. ${ }^{27,28}$ Hypertension patients were more likely to medication adherence, which is plausible because these patients might be also more controlled due to high blood pressure, and adherence in hypertension is higher compared to COPD, which could also influence adherence for COPD. ${ }^{29}$ Conversely, arthritis and osteoarthritis have not shown to be statistically significant, although these conditions contribute to an inability of device utilization. ${ }^{30}$ These results are likely to be explained by the constrained subsample size of these comorbidities; hence, further research is needed in this area.

Some patients failed to comply with physician's recommendations since they did not quit smoking (19\% of the sample). Smoking cessation is the most effective way of slowing the progression of this disease. ${ }^{12}$ Therefore, it is plausible to think that patients are also nonadherent to their medication. ${ }^{31}$ Indeed, our results suggest that the smoking men's probability of medication adherence decreased by $30 \mathrm{pp}$. Although sex was not crucial for explaining adherence, the negative effect of the interaction term between smoking status and men is considerable. The sample was mostly composed of men, who represent the common COPD patient. ${ }^{2}$ However, this pattern is changing since incidence of smoking, main cause of COPD, has increased in women, which have now greater health risks. ${ }^{2}$

Regarding health care utilization, we identified two effects of visiting the doctor. The effect of doctor visit would increase the probability of medication adherence. ${ }^{18}$ Conversely, patients who have visited their doctor more than three times per month were more likely to have suboptimal adherence. Results are feasible since health care professional interventions are consistently positive for adherence and compliance. ${ }^{32}$ However, many visits to the doctor negatively associated might indicate serious problems and patients are pushed to visit several times their physician. ${ }^{14,15,33}$ Cost was not finally statistically significant toward adherence. This is plausible since Spanish patients do not bear $100 \%$ of the pharmaceutical costs directly. ${ }^{34}$

These results should be interpreted within the context of study limitations. First, this is a retrospective study, which is vulnerable to bias. For instance, we could identify endogeneity in results for exacerbations, since it is likely that the causal direction goes from medication adherence toward exacerbations and not vice versa. ${ }^{13,35}$ Second, this study was conducted in a single health system; thus, results may not be extrapolate to other populations. However, trends are similar to previous research. ${ }^{17,20,23}$ Third, the assumption that obtaining prescription was equivalent to taking the medication, which might not be completely true. Moreover, our study approach to quantify adherence was done by using the MPR, which has 
been reported to be biased upward by previous research. ${ }^{9,14}$ Nevertheless, we tried to correct this by elevating the cutpoint, so fewer patients would be seen as adherent, and testing robustness of estimates due to this cut-point confirmed our findings. Actually since we obtain the persistence to COPD long-term medication, our estimates could be more accurate than those of few others who also used MPR without taking into account persistence. It is also true that tracking adherence patterns may imply to have data across time, which can be accomplished by analyzing adherence prospectively as well as analyzing other issues related with poor adherence that were not measured, such as intentional and nonintentional nonadherences, patients' preferences, and specific steps that the patients fail to complete within the process of taking their medicine. 5,36,37 The fact that NEXThaler ${ }^{\circledR}$ was introduced in 2012 could limit our study, but dataset provides a sufficient number of cases using NEXThaler ${ }^{\circledR}$ in order to be included within the DPI group. Finally, we could not obtain some patients' characteristics, such as race, level of education, type of job, and few others. This problem of data limitation also restricts our outcomes.

\section{Conclusion}

Medication adherence in COPD is crucial for optimizing clinical outcomes, and there are several factors that condition it. Inhaler devices are expected to help optimization of active ingredients. However, we found that DPIs included in our analysis $\left(\right.$ Turbuhaler $^{\circledR}$, Accuhaler $^{\circledR}$, and NEXThaler ${ }^{\circledR}$ ) delivering ICS/LABA FDCs had a negative effect on patients' medication adherence compared to pMDIs. The findings reviewed here suggest that the pharmacological effectiveness of the FDC, which seemed to be very promising in the beginning, might be conditioned by the inhaler technique associated with inhaler devices. The special feature of our findings is that we adjusted for the effects of the active ingredients in order to explore the specific effect of inhaler technique toward adherence. We have also corroborated that patients' clinic and demographic characteristics are associated with adherence.

Suboptimal adherence is a major problem in long-term therapies, such as COPD treatment. The consideration of incidence trends and risk factors related to COPD, in addition to the aging of population, makes very relevant to overcome barriers to treatment adherence in order to avoid progression of the disease and waste of resources because patients cannot obtain the maximum efficacy of their treatment, even among those who want to take their medicine correctly. Overcoming barriers passes through the innovation of inhaler devices. Instead of attributing all the responsibility of poor utilization due to human errors, more intuitive and simple designs are needed.

\section{Acknowledgments}

BCN Health Economics and Outcomes Research S.L., provided statistical analysis and editorial support.

\section{Disclosure}

This study was sponsored by Teva Pharmaceutical S.L.U. JD is employed by the University of Barcelona. GR is an employee of BCN Health Economics and Outcomes Research S.L., Barcelona, Spain, an independent contract health economic organization that has received research funding from TEVA Pharmaceutical S.L.U. AS is employed by Badalona Serveis Assistencials S.A. PF and RS are employed by TEVA Pharmaceutical Industries Ltd and they work in the Medical Department. ST is also employed by TEVA Pharmaceutical Industries Ltd. The authors report no other conflicts of interest in this work.

\section{References}

1. Grupo de trabajo de la Guía de Práctica Clínica para el Tratamiento del Pacientes con Enfermedad Pulmonar Obstructiva Crónica (EPOC) [Working Group of the Clinical Practice Guideline for the Treatment of Patients with Chronic Obstructive Pulmonary Disease (COPD)]. Plan de Calidad para el Sistema Nacional de Salud del Ministerio de Sanidad, Servicios Sociales e Igualdad. Unidad de Evaluación de Tecnologías Sanitarias de la Agencia Lain Entralgo [Quality Plan for the National Health System of the Ministry of Health, Social Services and Equality. Unit Health Technology Assessment of the Lain Entralgo Agency]; 2001. Guías de Práctica Clínica en el SNS: UETS n 2011/6.

2. Miravitlles M, Soler-Cataluña JJ, Calle M, et al. Spanish guideline for COPD (GesEPOC). Update 2014. Arch Bronconeumol. 2014;50(suppl 1): $1-16$.

3. Ancochea J, Miravitlles M, García-Río F, et al. Infradiagnóstico de la enfermedad obstructiva crónica en mujeres: cuantificación del problema, determinantes y propuestas de acción [Underdiagnosis of chronic obstructive pulmonary disease in women: quantificacion of the problem, determinants and proposed actions]. Arch Bronconeumol. 2013;49(6):223-229.

4. Inhaler Error Steering Committee, Price D, Bosnic-Anticevich S, et al. Inhaler competence in asthma: common errors, barriers to use and recommended solutions. Respir Med. 2013;107(1):37-46.

5. Melani AS, Bonavia M, Cilenti V, et al; Gruppo Educazionale Associazione Italiana Pneumologi Ospedalieri. Inhaler mishandling remains common in real life and is associated with reduced disease control. Respir Med. 2011;105:930-938.

6. Lavorini F, Fontana GA, Usmani OS. New inhaler devices - the good, the bad and the ugly. Respiration. 2014;88:3-15.

7. Roy A, Battle K, Lurslurchachai L, Halm EA, Wisnivesky JP. Inhaler device, administration technique and adherence to inhaled corticosteroids in patients with asthma. Prim Care Respir J. 2011;20(2):148-154.

8. Cramer JA, Roy A, Burrell A, et al. Medication adherence and persistence: terminology and definitions. Value Health. 2008;11(1): 44-47.

9. Christensen AJ. Patient Adherence to Medical Treatment Regimens: Bridging the Gap Between Behavioral Science and Biomedicine. New Haven, CT: Yale University Press; 2004. 
10. Rolnik S, Pawloski PA, Hedblom BD, Asche SE, Bruzek RJ. Patient characteristics associated with medication adherence. Clin Med Res. 2013; 11(2):54-65.

11. World Health Organization (WHO). Adherence to Long-Term Therapies: Evidence for Action. Geneva, Switzerland; 2003. Available from: http://www.who.int/chp/knowledge/publications/adherence_report/en/. Accessed December, 2014.

12. From The Global Strategy for the Diagnosis, Management and Prevention of $C O P D$, Global Initiative for Chronic Obstructive Lung Disease (GOLD); 2015. Available from: http://www.goldcopd.org/. Accessed March, 2015.

13. Williams LK, Pladevall M, Xi H, et al. Relationship between adherence to inhaled corticosteroids and poor outcomes among adults with asthma. J Allergy Clin Immunol. 2004;114(6):1288-1293.

14. Claxton AJ, Cramer J, Pierce C. A systematic review of the associations between dose regimens and medication adherence. Clin Ther. 2001; 23(8):1296-1310.

15. Barnestein-Fonseca P, Leiva-Fernández J, Vidal-España F, García-Ruíz A, Prados-Torres D, Leiva-Fernández F. Is it possible to diagnose the therapeutic adherence of patients with COPD in clinical practise? A cohort study. BMC Pulm Med. 2011;11:6.

16. Stern L, Berman J, Lumry W, et al. Medication adherence and disease exacerbation in patients with asthma: a retrospective study of managed care data. Ann Allergy Asthma Immunol. 2006;97(3):402-408.

17. Steiner JF, Prochazka AV. The assessment of refill adherence using pharmacy records: methods, validity and applications. J Clin Epidemiol. 1997;50(1):105-115.

18. Hughes D, Cowell W, Koncz T, Cramer J; International Society for Pharmacoeconomics and Outcomes Research Economics of Medication Adherence Working Group. Methods for integrating medication adherence and persistence in pharmacoeconomic evaluations. Value Health. 2007;10(6):498-509

19. Lavorini F, Magnan A, Dubus JC, et al. Effect of incorrect use of dry inhalers on management of patients with asthma and COPD. Respir Med. 2008;102(4):593-604.

20. Bryant J, McDonald VM, Boyes A, Sanson-Fisher R, Paul C, Melville J. Improving medication adherence in chronic obstructive pulmonary disease: a systematic review. Respir Res. 2013;14:109.

21. Pedersen S, Frost L, Arnfred T. Errors in inhalation technique and efficiency of inhaler use in asthmatic children. Allergy. 1986;41: $118-124$.

22. Khassawneh BY, Al-Ali MK, Alzoubi KH, et al. Handling of inhaler devices in actual pulmonary practice: metered-dose inhaler versus dry powder inhalers. Respir Care. 2008;53(3):324-328

23. Molimard M, Raherison C, Lignot S, Depont F, Abouelfath A, Moore N. Assessment of handling of inhaler devices in real life: an observational study in 3811 patients in primary care. J Aerosol Med. 2003; 16(3):249-254.
24. Crompton GK, Barnes PJ, Broeders M, et al; Aerosol Drug Management Improvement Team. The need to improve inhalation technique in Europe: a report from the Aerosol Drug Management Improvement Team. Repir Med. 2006;100(9):1479-1494.

25. Epstein S, Maidenberg A, Hallet D, Khan K, Chapman KR. Patient handling of a dry-powder inhaler in clinical practice. Chest. 2001;120: $1480-1484$.

26. Gellad WF, Grenard JL, Marcum ZA. A systematic review of barriers to medication adherence in the elderly: looking beyond cost and regimen complexity. Am J Geriatr Pharmacother. 2011;9(1):11-23.

27. Billups SJ, Malone DC, Carter BL. The relationship between drug therapy nonadherence and patient characteristics, health-related quality of life, and healthcare cost. Pharmacotherapy. 2000;20:941-949.

28. Turner J, Wright E, Mendella L. Predictors of patient adherence to long-term home nebulized therapy for COPD. The IPPB study group. Intermittent positive pressure breathing. Chest. 1995;108:394-400.

29. Cramer JA, Benedict A, Muszbek N, Keskihaslan A, Khan ZM. The significance of adherence and persistence in the treatment of diabetes, hypertension and dyslipidaemia: a review. Int J Clin Pract. 2008;62(1): 76-87.

30. Taffet GE, Donohue JF, Altman PR. Considerations for managing chronic obstructive pulmonary disease in the elderly. Clin Interv Aging. 2014;9:23-30.

31. Krigsman K, Nilsson JL, Ring L. Adherence to multiple drug therapies: refill adherence to concomitant use of diabetes and asthma/COPD medication. Pharmacoepidemiol Drug Saf. 2007;16:1120-1128.

32. Mansur N, Weiss A, Hoffman A, Gruenewald T, Beloosesky Y. Continuity and adherence to long-term drug treatment by geriatric patients after hospital discharge. Drugs Aging. 2008;25(10):861-870.

33. Dalcin Pde T, Grutcki DM, Laporte PP, et al. Impact of short-term educational intervention on adherence to asthma treatment and on asthma control. J Bras Pneumol. 2011;37(1):19-27.

34. Ley $29 / 2006$, de 26 de Julio, de garantías y uso racional de los medicamentos y productos sanitarios. BOE num 178: 28122-28165 [Law $29 / 2006$ of July 26 , on guarantees and rational use of medicines and health products. BOE $\left.N^{\circ} 178: 28122-28165\right]$. Available from: http:// www.boe.es/buscar/doc.php?id=BOE-A-2006-13554

35. Garcia-Aymerich J, Farrero E, Félez MA, et al; Estudi del Factors de Risc d'Agudització de la MPOC investigators. Risk factors of readmission to hospital for a COPD exacerbation: a prospective study. Thorax. 2003;58(2):100-105.

36. Clifford S, Barber N, Horne R. Understanding different beliefs held by adherers, unintentional nonadherers, and intentional nonadherers: application of the necessity-concerns framework. J Psychosom Res. 2008; 64(1):41-46.

37. Chrystyn H, Small M, Milligan G, Higgins V, Gil EG, Estruch J. Impact of patients' satisfaction with their inhalers on treatment adherence and health status in COPD. Respir Med. 2014;108(2):358-365.
International Journal of COPD

\section{Publish your work in this journal}

The International Journal of COPD is an international, peer-reviewed journal of therapeutics and pharmacology focusing on concise rapid reporting of clinical studies and reviews in COPD. Special focus is given to the pathophysiological processes underlying the disease, intervention programs, patient focused education, and self management protocols.

\section{Dovepress}

This journal is indexed on PubMed Central, MedLine and CAS. The manuscript management system is completely online and includes a very quick and fair peer-review system, which is all easy to use. Visit http://www.dovepress.com/testimonials.php to read real quotes from published authors. 